\title{
Photovoltaic Materials and Devices
}

\author{
Bhushan Sopori, ${ }^{1}$ Teh Tan, ${ }^{2}$ and Peter Rupnowski ${ }^{3}$ \\ ${ }^{1}$ National Renewable Energy Laboratory, 1617 Cole Boulevard, Golden, CO 80401, USA \\ ${ }^{2}$ Department of Mechanical Engineering and Materials Science, Duke University, Durham, NC 27706, USA \\ ${ }^{3}$ Dow Corning Corporation, 2200 W Salzburg Road, Midland, MI 48686, USA
}

Correspondence should be addressed to Bhushan Sopori, bhushan_sopori@nrel.gov

Received 3 April 2012; Accepted 3 April 2012

Copyright ( 2012 Bhushan Sopori et al. This is an open access article distributed under the Creative Commons Attribution License, which permits unrestricted use, distribution, and reproduction in any medium, provided the original work is properly cited.

As the global energy needs grow, there is increasing interest in the generation of electricity by photovoltaics (PVs) devices or solar cells-devices that convert sunlight to electricity. Solar industry has seen an enormous growth during the last decade. The sale of PV modules has exceeded $27 \mathrm{GW}$ in 2011, with significant contributions to the market share from all technologies. While the silicon technology continues to have the dominant share, the other thin film technologies (CdTe, CIGS, a-Si, and organic PV) are experiencing fast growth. Increased production of silicon modules has led to a very rapid reduction in their price and remains as benchmark for other technologies. The PV industry is in full gear to commercialize new automated equipment for solar cell and module production, instrumentation for process monitoring technologies, and for implementation of other cost-reduction approaches, and extensive research continues to be carried out in many laboratories to improve the efficiency of solar cells and modules without increasing the production costs. A large variety of solar cells, which differ in the material systems used, design, PV structure, and even the principle of $\mathrm{PV}$ conversion, are designed to date.

This special issue contains peer-reviewed papers in the recent developments in research related to broad spectrum of photovoltaic materials and devices. It contains papers on many aspects of solar cells-the growth and deposition, characterization, and new material development.

\section{Acknowledgment}

The editors acknowledge with thanks the contributing authors for the work they have put in participation and reviewers for ensuring good quality and the staff at the Hindawi Publishing Corporation for their helpful assistance and efficient handling of the publication. They are thankful to Dr. Sudhakar Shet, National Renewable Energy Laboratory, for his assistance in preparing this special issue. The support of Mona Mahmoud, Editorial Office, Hindawi Publishing Corporation is gratefully acknowledged.

Bhushan Sopori Teh Tan Peter Rupnowski 


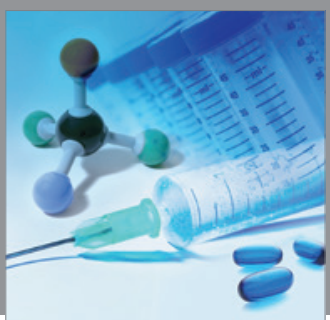

International Journal of

Medicinal Chemistry

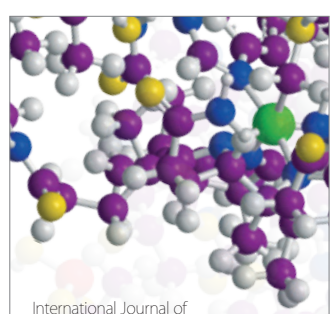

Carbohydrate Chemistry

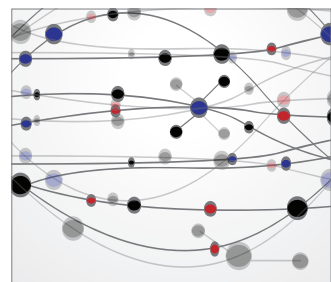

The Scientific World Journal
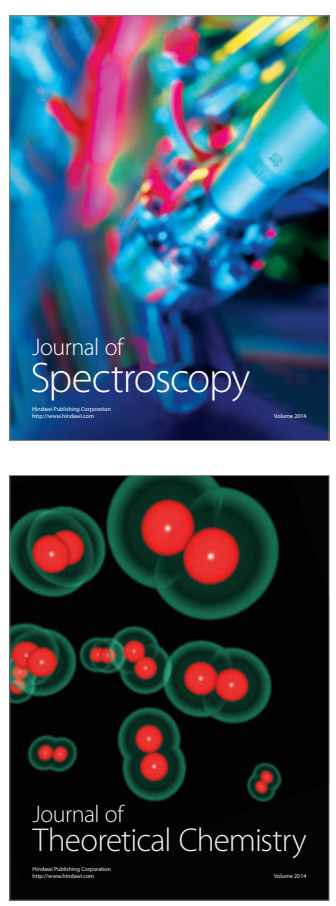
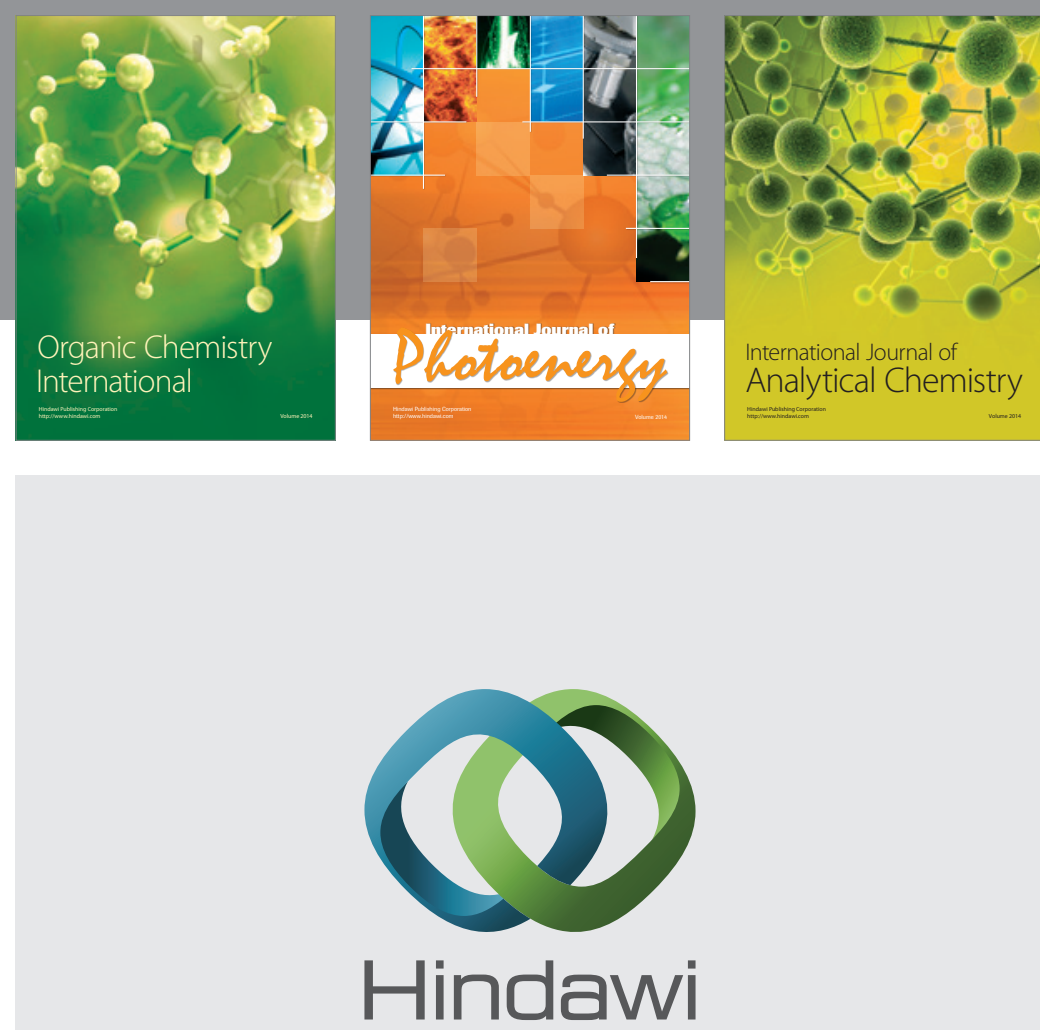

Submit your manuscripts at

http://www.hindawi.com
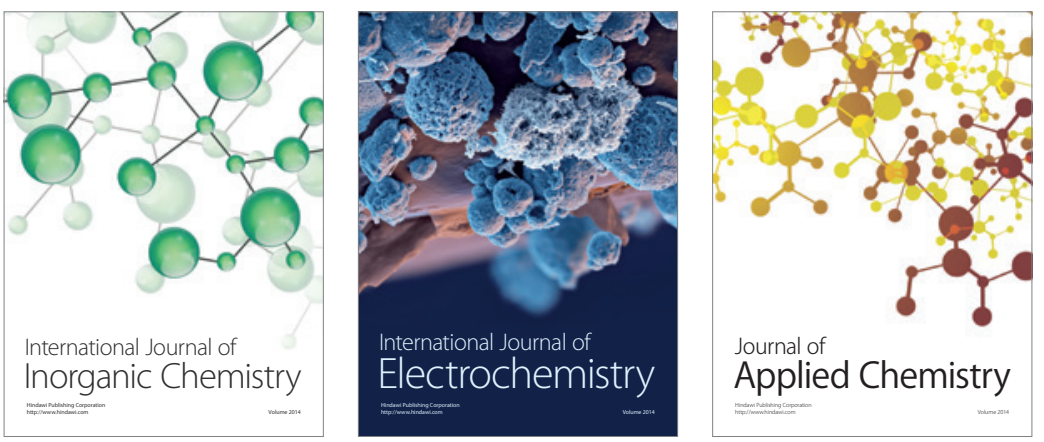

Journal of

Applied Chemistry
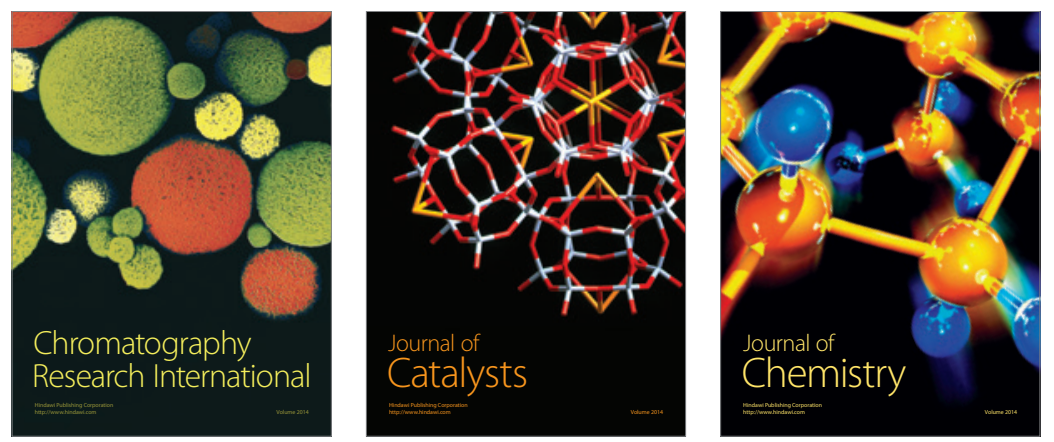
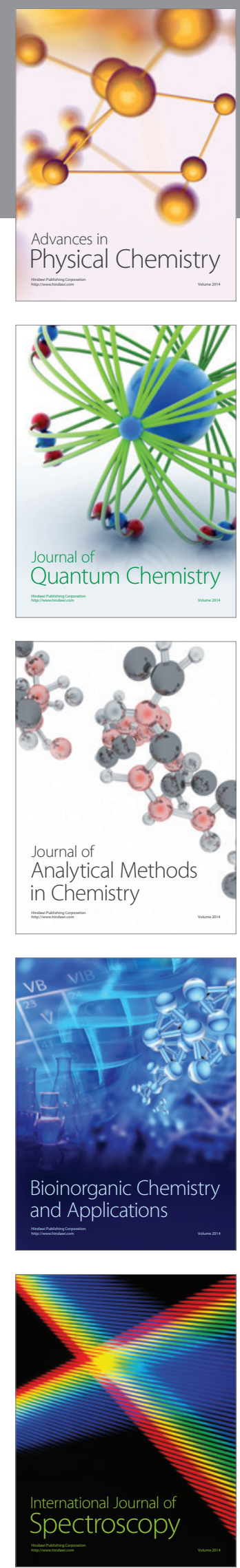